\title{
Forestry Software Customization Design Based on Open Source
}

\author{
Huiliang Duan \\ The network center, Central South University of Forestry and Technology, Changsha, 410004, \\ China
}

Keywords: forestry information systems, software customization platform, open source framework

\begin{abstract}
Set up the framework of the forestry information systems software custom development platform based on open source software. Implements the data, general template, tools coarse-grained components of sharing. At the same time, the framework component coupling, convenient for function extension and modification. Framework implement the software customization, and support program code automatically generated, code generator generates code is simple in structure, convenient for secondary development.
\end{abstract}

\section{Introduction}

Forestry informationization is an important content of the forestry modernization, accelerate the forestry informationization, is helpful to build up forestry information system at all levels. To improve the forestry information management and service level, promote forestry sustainable development is of important theoretical and practical significance. Software custom development is a form of software development. In China, custom software development is a new thing, has not been agreed by the customers. Forestry information system platform is a software custom development which do not need to write code or just write a few function extension code can quickly build the forestry information systems. Forestry information system customization platform will change the way of forestry information system construction. By use of forestry software customization platform, to get rid of the technical details, developers can focus on the business requirements and management problems of the forestry information systems, will improve the efficiency of the information systems development.

\section{General custom software and software platform}

Software users have special requirements for a software system, especially in the industry and industry demand for personalized distinctive. Common software is usually use suite of thoughts and the mode of management, completely let customers according to the streamline form of business process management, which don't consider both the industry and internal personalized demand, thus causing the software in the process of online has to face a serious of problem.

No matter what kind of application system, will have basic function, such as add data or delete. Software customization platform abstracts these commonness, by uses templates, resource sharing in order to save development costs, improve the development efficiency, shorten the development cycle. Software development participants cooperated through the network, greatly improve the efficiency of software development. Custom software development based on web, should have the following features:

Software based on B/S architecture of the Internet. The web itself is also a software, not the final software product, but the software for secondary development.

Different from the traditional development tools, you needn't write code to complete each module by use of web development platform tools. secondary development platform based on the web only need to design their own data structures, carry on some simple configuration, such as drag operation can be completed for the development of business systems.

Including complex chart report design, traditional coding type development needs to want to write reports, and using the development platform through configuration should be able to produce the corresponding reports. 


\section{Present situation of Forestry information system data sharing}

At present, the research and development of the forestry information system is based on different technical architecture, developed by different technology units; Their language platform, data structure, running environment, there are different degrees of difference; Provide business functions and information services is different also, forming many information islands, lead to share data barrier among different business[1]; most of forestry information system without foreign development extension interface, Makes the system difficult to extend. At present, to solve the above problems, the industry commonly used technical architecture is based on WCF and Web Service framework or based on service oriented architecture (SOA).

Web services use Extensible markup language (XML) to represent data, it uses simple object access protocol (Soap) to implement data interaction between applications in a distributed environment. WSDL to implements the service interface, In addition, in order to find by other user, Web services can register to the UDDI center.

Service oriented architecture (SOA) is a software project development and information systems construction method in recent years, on behalf of an open, extensible, secure and the combination of software architecture, SOA is a loosely coupled application architecture, Service layer be added between the business layer and presentation which achieve a specific Service function, make the business layer and presentation layer are independent of each other [2].

Since January, 2014, “General Specification for Design of Database of Forestry” has been released, the specification provides a solid foundation for forestry data sharing. Using Web services framework and based on Service oriented architecture (SOA) in a certain extent, can solve the problem of data sharing, but will not able to satisfy the needs of business rapid development and application rapid online[3].

\section{Custom software platform based on open source framework}

\subsection{Technical framework}

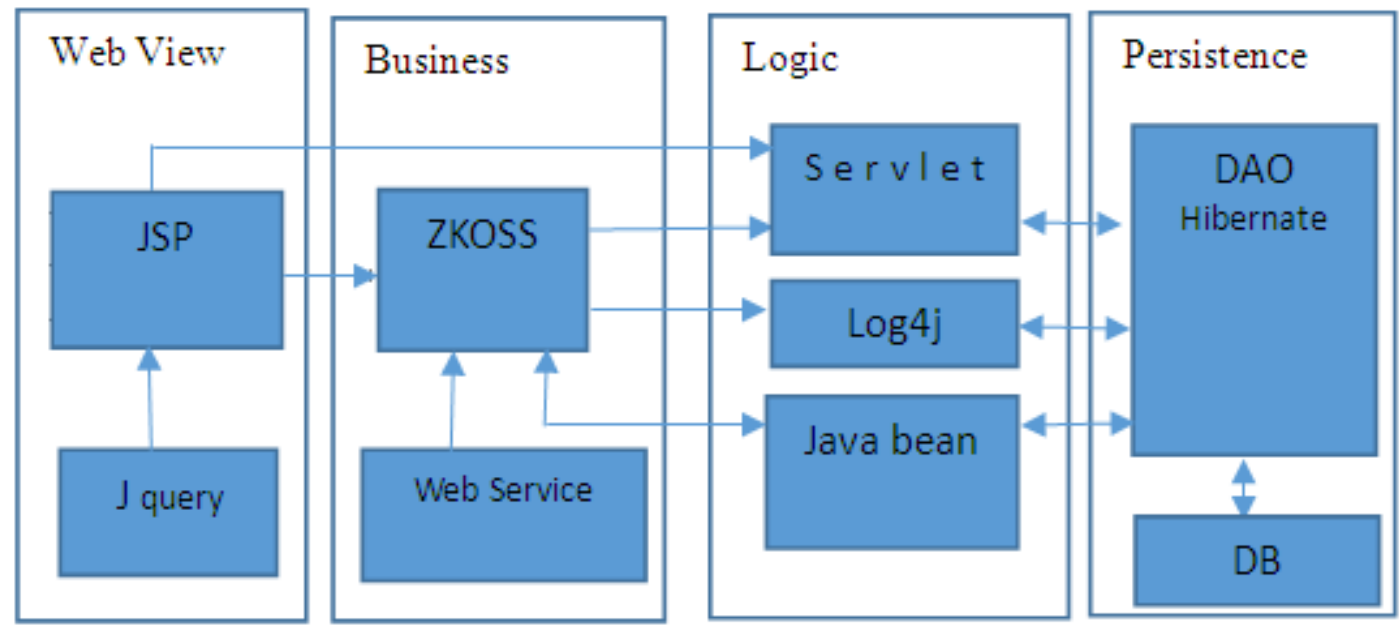

Fig.1 Technical framework

ZKOSS is asynchronous AJAX technology, providing a complete set of the business logic of the interface communication solution, which is one of the three major RIA (Rich Internet Applications) .A technology used on the case of many people online at the same time, data communication is concentrated, which can effectively control the resource usage, reduce the pressure of the server.

Hibernate is an open source object-relational mapping framework, has carried on the very lightweight object to JDBC encapsulation, it is an object-oriented domain model to a traditional relational database mapping, framework provides an easy to use. At the same time, the framework is currently accepted JAVA data persistence layer technology, to reduce the programmer construction, standardized code, easy to maintenance. 
The Spring framework provides a full-featured MVC module build Web applications. MVC as the core part of the WEB project development, the controller user client is separated from business constitutes the MVC, the Spring framework is highly configurable, and contains the JSP technology, iText, and POI and various view technologies.

Jquery a good Java script framework. It is a lightweight js library, put part of the business client processing, reducing the pressure of server part and reduce server resource usage, can be compatible with various browsers, can more easily handle HTML documents, events, to achieve animation effects, and easily provide AJAX interaction for the web site.

All the above technical framework based on JAVA development language, technical framework. Framework of every technological have at least 5 years of history, has experienced several version update, is verified by practice of multiple projects. The framework mainly embodies the following characteristics:

The structure is clear, standardized writing, convenient maintenance;

Make full use of the client, application server and database server, At the same time, considering pressure and load balancing;

Clear hierarchy, modular design, convenient and functional extension;

Strict hierarchy, for the safety of the whole system with layers of protection.

\subsection{Functional design}

Based on the above open source framework, software customization platform has the following functions and features: Support mainstream database; Realization of code automatically generated; Support for multiple data model; Dependence of the code generator is low; Convenient extension ability.

Framework convenient for function extension and modification, general SQL queries without code to write, through the page dynamic query field, to realize the automatic query custom; Tool class implements the common packaging, import and export documents which can meet the major of information project needs; Integrated Reporting tool ,convenient image report ,data export or generate PDF, excel and word format report. The framework functional shown as figure 2.
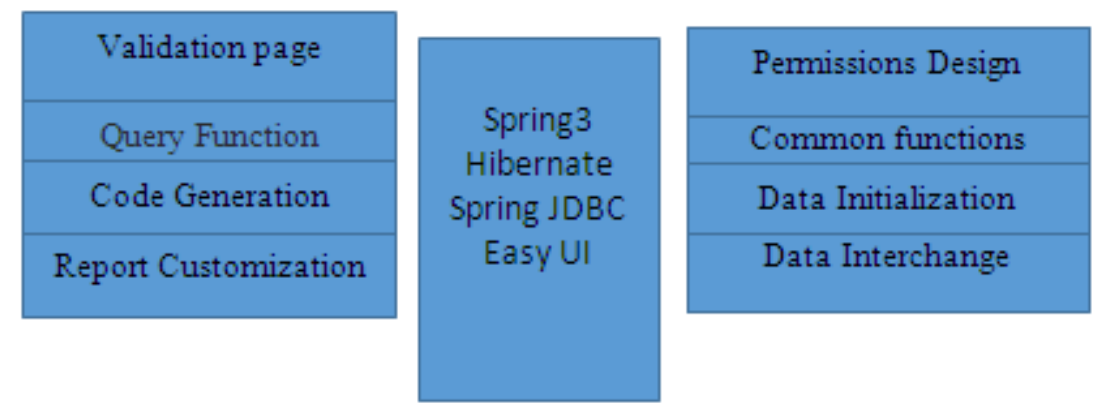

\subsection{Code automatically generated}

Fig.2 Function of the Framework

By reading the table structure and the field properties, Customization Platform can generate a unified Page, Page validation and standardize the code (Action, Service, Dao, the Entity, Page, etc.). In the meantime, out of the framework, realize the decoupling design makes the struts2, Spring MVC, Hibernate, Mybatis, EasyUI, DWZ and ExtJS technique can be used in flexible combination[4][5].

\subsubsection{Data acquisition and system configuration}

Establish a database table in the database, each field annotated and code generator page fields will according to the comments to generate the corresponding display text.

The code generator, there are two configuration files: one for the data source configuration (database.properties), another one for the code generator parameter configuration (config.Properties). the code generator uses the template file directory, program coding, custom named main contents such as the primary key.

\subsubsection{Code generation}

Open the code generator and input the corresponding parameters, as shown in figure 3. 


\begin{tabular}{|c|c|c|}
\hline \multicolumn{3}{|l|}{ 提示: } \\
\hline 包名（小写）： & \multicolumn{2}{|l|}{ person } \\
\hline 实体卷名（首字母大写）： & \multicolumn{2}{|l|}{ Person } \\
\hline 表名： & \multicolumn{2}{|l|}{ person } \\
\hline 主镍生成策略： & uuid & $\nabla$ \\
\hline \multicolumn{3}{|l|}{ 主䁛SEQUENCE : (oracle序列名) } \\
\hline 功能魥述： & \multicolumn{2}{|l|}{ 员工信息 } \\
\hline 行字段数目： & \multicolumn{2}{|l|}{1} \\
\hline$\nabla$ Action & \multicolumn{2}{|l|}{$\nabla$ Jsp } \\
\hline$\checkmark$ Servicel & \multicolumn{2}{|l|}{$\nabla$ Servicelmpl } \\
\hline$\nabla$ Page & \multicolumn{2}{|l|}{$\nabla$ Entity } \\
\hline - Table风挌(form) & \multicolumn{2}{|l|}{ Div风格(form) } \\
\hline 生成 & \multicolumn{2}{|l|}{ 退出 } \\
\hline
\end{tabular}

Fig.3 The Code Generator

Perform "generation", in the source directory can see the new generation of Java code, in the same way, new automatically generated JSP page can see in the directory of web/pages.

\section{5. summary}

On the basis of software customization platform, through the integration of various kinds of basic data of forestry, can quickly and efficiently develop all kinds of forestry information system. At present, the main functions of the platform has realized, forestry based data acquisition and conversion need further perfection and improvement. The function of the software custom development platform still need further perfect.

\section{References}

[1]PANG Li-feng, TANG Xiao-ming, LIU Peng-ju. Development of the Provincial Forestry Information Sharing Platform Based on WebGIS. Journal of Northwest Forestry University, 26(2)pp. 180-184,2011.

[2]CAO Dan. Preliminary Study on Framework Design for Data Sharing Platform of Forest Resource, Forest Inventory and Planning,34( 4) pp.58-60,2009 .

[3]ZHANG Xi-ke, ZHANG Gui. Study on customization technology of forestry information system . Journal of Central South University of Forestry \& Technology,33 ( 5),pp.35-40,2013

[4]Peng Huanke Liu Xudong Zhang Wenyi. The Research and Application of Domain-oriented Software Customization Development Method. Computer Engineering and Applications, pp. 85-87,2005

[5]Wang Zhonglin Yin Baolin. Prototype Selection of Customized Development Process Based on Opensource Software. Journal of Beijing University of Aeronautics and Astronautics,32 (12)pp.1490-1494,2006 